\title{
Zealots' effect on opinion dynamics in complex networks
}

\author{
Moeinifar V. ${ }^{1}$, Gündüç S. ${ }^{2}$ \\ Department of Computer Engineering, Faculty of Engineering, Ankara University, Ankara, Turkey
}

(Received 17 August 2020; Revised 16 March 2021; Accepted 16 March 2021)

\begin{abstract}
In this paper, we study zealots' effects on social networks. Our social network is based on scale-free networks using Barabasi-Albert method and random networks using ErdôsRényi method. We used a pre-studied modified Voter model that includes zealots, individuals who never change their opinions. We chose prominent individuals (i.e. hubs) as zealots. In this way we first chose important individuals with high degree (hubs); second, individuals with high closeness. And then examined the consensus time compared with that zealots are chosen as non-important individuals. We found that the time to get to the consensus state in social networks is the same for different numbers of zealots but with the same degrees of contamination with zealotry. For example, one zealot's effect with a degree of 64 is same to 8 zealots' effects with a degree of 8 .
\end{abstract}

Keywords: voter model, zealot, random, scale-free, networks, Erdốs-Rényi, BarabasiAlbert, hub, closeness, centrality.

2010 MSC: 91D30, 05C 82

DOI: $10.23939 / \mathrm{mmc} 2021.02 .203$

\section{Introduction}

The development process of models describing the dynamics competition between two spins or opinions has to make researchers introduce a variety of models. Some of these models assume that opposite units of society include \pm 1 opinions so those units are constantly in conflict to achieve the social consensus state with their own opinion (Ising Model). The Ising model, with its simplicity, wide application, and utility for understanding phase transition, has a special attention in statistical mechanics studying [1].

The voter model, an Ising-like model [2], is one of these models that describes the competition of individuals [3]. The model assumes the opinion of individuals to be a \pm 1 discrete variable. This model describes the consensus formation in some population of individuals [1]. Every individual has a spin as +1 or -1 that is in a competition that this competition changes the spines. At each time step, a randomly chosen individual will copy one of his/her randomly neighbor opinions. In this opinion dynamic model, a population of individuals that act as voters in finite-size come to consensus in a time that depends on the network size, the spatial dimension (network type), and the number of opinions [1].

In the voter model, there are two basic update rules introduced by Glauber and Kawasaki [4]. In Glauber's dynamics, the dynamics is based on individuals, while in Kawasaki's dynamics of two neighbors change their opinions. Therefore, the Glauber's and Kawasaki's dynamics give a different result of scaling laws for domain growth in coarsening processes [5]. In Glauber voter update model at each time step, a random individual will be selected, who then copies the opinion of one random neighbor. However, in Kawasaki's voter update, at each time step a random pair of nearest-neighbors are selected, and an opinion of +1 or -1 is assigned to both of them if they have different opinions; and they will be left unchanged if they have the same opinions [6].

In this work, we have used a modified voter model that the population includes a small number of individuals called zealots that never change their opinions. Because of the effect of zealots on social consensus achievement, they have attracted much attention $[4,7,8]$.

The zealots have been studied in $[9,10]$. In Naoki work, the hubs are chosen as zealots to control the opinion dynamic in network [9]. 
In this paper, firstly, we directly calculate the magnetization of network without any zealots. Then opinion dynamics in network, by choosing different numbers of zealots with a certain degree.

Zealots even in a small fraction of the population can substantially change the dynamics. In the previous studies, one zealot's [7] and a small number of zealots' [8] effects on the voter model were discussed. Even, a few numbers of zealots can lead the population to a steady-state with a low magnetization distribution fluctuate around a value [7].

In this paper, we choose scale-free network and Random network as our network type. Nodes degree distribution in a scale-free network, follows a power law. It means that when the network grows, the underlying structure remains the same. The most important property of a scale-free network is hub which its degree greatly exceeds the average degree of other nodes. The preferential attachment model ('rich gets richer') is the most common model that generates hubs in a complex network. An important property of many large networks is the distribution degree that follows a scale-free power-law distribution [11].

The process of choosing these individuals effectively changes the dynamics of the population's opinion. Individuals that greatly exceed the average neighbors (hubs) or with high closeness centrality are our targets to study. Here, we first try to extract the hubs of the network and make them into a zealot. The emergence of hubs is a direct result of a scale-free property of networks [12]. The importance of hubs has been studied by Barabasi et al. The author(s) showed the role of hubs in sustainability of scale-free networks. And showed that how an attack on hubs can extremely change the network structure [13]. Hubs commonly are aged nodes in a complex network. Two essential aspects make scale-free networks different from random networks. First is the growth property of the network that generates hubs, so the hubs are more aged nodes in a scale-free network. The second aspect that makes these two networks different is the preferential attachment of nodes. These two differences at the same time are reasons of the emergence of hubs [14].

The other way we tried to investigate the zealots' effect is by choosing individuals according to their closeness. High closeness centrality is a good measure that can make an individual more effective in opinion dynamics. As we investigate, zealots with higher closeness are more effective in increasing consensus achievement time. Closeness was defined by Bavelas (1948) as the reciprocal of the farness [15]. He has shown the idea of centrality as applied to human communication. In a connected graph, closeness centrality of a node is a measure that calculates the centrality of a node in a network. Thus, the closer a central node is to all other nodes, the more important it is in social communication studies. Closeness centrality, one of the well-known global measurements of complex networks, is widely applied to many researches. Cohn and Marriott (1958) used the centrality in their study to understand political integration in the context of the diversity of Indian social life [16].

Another complex network we use to examine the effect of zealots, is random network. A random network is a network that refers to probability distributions. In Section 4, we will explain more about the random network and the algorithm we used to generate it.

Previously, the role of persuasion power on the consensus formation was studied in [17]. In that paper an opinion dynamics model which is based on a version of two dimensional Sznajd model is introduced. According to this model, the dynamics is governed by the interactions between four agents who live on the corners of a plaquette and their neighbors. The distinctive feature of the model is that each individual is identified by two parameters, namely, opinion and persuasion ability. The united group may persuade the individuals living at the neighboring sites according to both the number and their persuasion ability. Also in other paper [18], we studied the role of fanatics in consensus formation. A model of opinion dynamics with two types of agents as social actors are presented, using the Ising thermodynamic model as the dynamics template. The agents are considered as opportunists which live at sites and interact with the neighbors or fanatics/missionaries who move from site to site randomly in persuasion of converting agents of opposite opinion with the help of opportunists.

In this paper as another approach, we study the effects of zealots on the population consensus. Our generation is on both simulated network and real network. 
In the next section we explain our model. Then, we try to investigate the effect of zealots on opinion dynamics. After that, we use hubs as zealots and see that the consensus achievement will increase more rapidly in comparison to the same number of zealots that are not hubs. In random networks, to achieve an early consensus, we have to choose more individuals as zealots while in scale-free networks hubs even in a small fraction are more effective.

\section{Model}

Our model is a pre-studied modified Voter model based on zealots. Similar to original voter model, the population includes individuals as voters with two \pm 1 opinions. In the original voter model, each individual is susceptible $(\sigma)$, which means that all individuals can change their opinions. In our model, individuals are parted into two groups, susceptible and zealots $(z)$. Zealots are unsusceptible, which means that they never change their opinions. In this situation, distributing the same number of zealots on each side of positive opinions $(+1)$ and negative opinions $(-1)$, will not change the opinion dynamics of the population, and opposing zealots will counteract the effects.

The original voter model includes individuals as voters with two opinions $\sigma_{i} \rightarrow \pm 1$, spins up or down. At each iteration, one randomly selected individual will copy one of his/her neighbors' opinion. In a network, two individuals are the nearest neighbors if they are connected via a direct link. Therefore, the probability that a spin changes is given by [19]:

$$
P\left(\sigma_{i} \rightarrow-\sigma_{i}\right)=\frac{1}{2}\left(1-\frac{\sigma_{i}}{k_{i}} \sum_{j \in v_{i}} \sigma_{j}\right),
$$

where $k_{i}$ is the degree of individual $i$, it shows the number of neighbours of individual $i$, and $v_{i}$ is the neighbourhood of individual $i$, it is the list of nearest neighbouring individuals of individual $i$.

In confronting with this update rule, a randomly selected individual would have three cases:

1. If all neighbours of the randomly selected individuals are in agreement with him/her then the probability to change the opinion is $0\left(P\left(\sigma_{i} \rightarrow-\sigma_{i}\right)=0\right)$.

2. If all of the neighbours disagree with the individual, then: $P\left(\sigma_{i} \rightarrow-\sigma_{i}\right)=1$.

3. Otherwise, the individual opinion may change or not and it all depends on the neighbors $\left(k_{i}\right)$ and neighborhood $\left(v_{i}\right)$.

Here, in our model, if the randomly selected individual will change his/her opinion if and only if he/she is susceptible (unsusceptible who we refers as zealots will never changes their opinions). Therefore, the probability that an individual changes his/her opinion is given by:

$$
P\left(\sigma_{i} \rightarrow-\sigma_{i}\right)=\frac{1}{2}\left(1-\frac{\sigma_{i}}{k_{i}} \sum_{j \in v_{i}} \sigma_{j}\right) \quad \text { iff } \quad \sigma \neq z .
$$

Before we start simulating the opinion update, we give some of the individuals a flag of 1 and 0 . Flag 1 means that the individual is a zealot. This selection will explain in the relevant section. Our network size is 1024 (at each scale-free or random network. We also generate our model on a real network with 2288 nodes in section 5). Each individual of this network has a +1 or -1 opinion. The initial population (population at $t_{0}$ ) of +1 and -1 opinions is the same:

$$
N_{+}^{t_{0}}=N_{-}^{t_{0}}
$$

$N_{+}^{t_{0}}$ refers to the population with +1 opinion at time 0 , and $N_{-}^{t_{0}}$ refers to population with -1 opinion at time 0 .

Depending on our update rule, at each iteration 8 individuals (or not) change their opinion. If the randomly selected individual is a zealot, then the iteration will be repeated till a non-zealot(susceptible) individual is selected.

Although zealots never change their opinions, they actively participate in the opinion updates and can persuade others by rate 1 , like other individuals. Means the persuasion strength that we set to 1 , 
which a randomly chosen susceptible will copy one of his/her neighbors' opinion with probability of 1 . Here, in confronting with this modified update rule, a randomly selected individual will have three cases:

1. If and only if, the randomly selected individual is non-zealot and all of his/her neighbours are in agreement, then the probability to change the opinion is $0\left(P\left(\sigma_{i} \rightarrow-\sigma_{i}\right)=0\right)$.

2. If and only if, the randomly selected individual is non-zealot and all of his/her the neighbours disagree, then: $P\left(\sigma_{i} \rightarrow-\sigma_{i}\right)=1$.

3. Otherwise, If and only if, the randomly selected individual is non-zealot, the individual opinion may change or not and it all depends on the neighbors $\left(k_{i}\right)$ and neighborhood $\left(v_{i}\right)$, (see Eq. (1))

At the first state, we set the zealots only on the positive side. That means all of the zealots' opinions are 1. After that, we will set the zealots either on the positive or the negative sides and then we will compare the consensus achievement in both states.

At initial states, we randomly distribute +1 and -1 opinions on the network. Thus, the population of +1 opinions and -1 opinions are the same.

To normalize the positive and negative population we used Eq. (4) as below:

$$
d_{+}(t)=\frac{Z_{+}+S_{+}(t)}{N}, \quad d_{-}(t)=\frac{\sigma_{-}(t)}{N},
$$

where $d_{ \pm}(t)$ denotes the density of positive or negative population at time $t$, respectively. The whole network opinion described as magnetization, can be calculated as below:

$$
m(t)=d_{+}(t)-d_{-}(t) .
$$

It is common to calculate the mean population opinion to investigate the consensus achievement. To calculate the mean magnetization, we denote $|m|$ by:

$$
|m|=\frac{N_{+}-N_{-}}{N_{+}+N_{-}}
$$

\section{Generation of simulated data set (scale-free network)}

\subsection{Scale-free network model}

Firstly we examine our model on a scale-free network. This network is generated based on BarabásiAlbert's model [14] with 1024 nodes and 8000 links (approx.). The average nodes degree is $8(\langle k\rangle$ is $8)$. By the emergence of scale-free networks, a variety of complex systems such as nature and social networks, biological cells or the Internet, could be described by this type of complex network [14]. In the case of the social population simulation, scale-free networks with hubs as zealots can be an interesting study. Hubs with a high degree can extremely change opinion dynamics.

\subsection{The algorithm of scale-free network}

To generate the scale-free network we first identify two nodes with ID 0 and node with ID 1 (the initial network is $n_{0}$ ). There is only one connection and this is between node 0 and node 1 . At each time step 8 link will be added to the network. A new node will be added to the network and will connect with $n \leqslant n_{0}$ nodes. This connection is based on preferment attachment, i.e. that nodes with higher degree will be more probable to connect to the new arrived node. This time steps will be repeated until our network size (1024).

Firstly, we choose $0,2,4,8,16,32$ and 64 individuals as zealots all with the same degree of 8 . Initial population of positive and negative opinions are the same. In Fig. 1, we investigate the role of zealots in consensus achievement. As shown below, the number of zealots is reverse related to the population consensus time. 


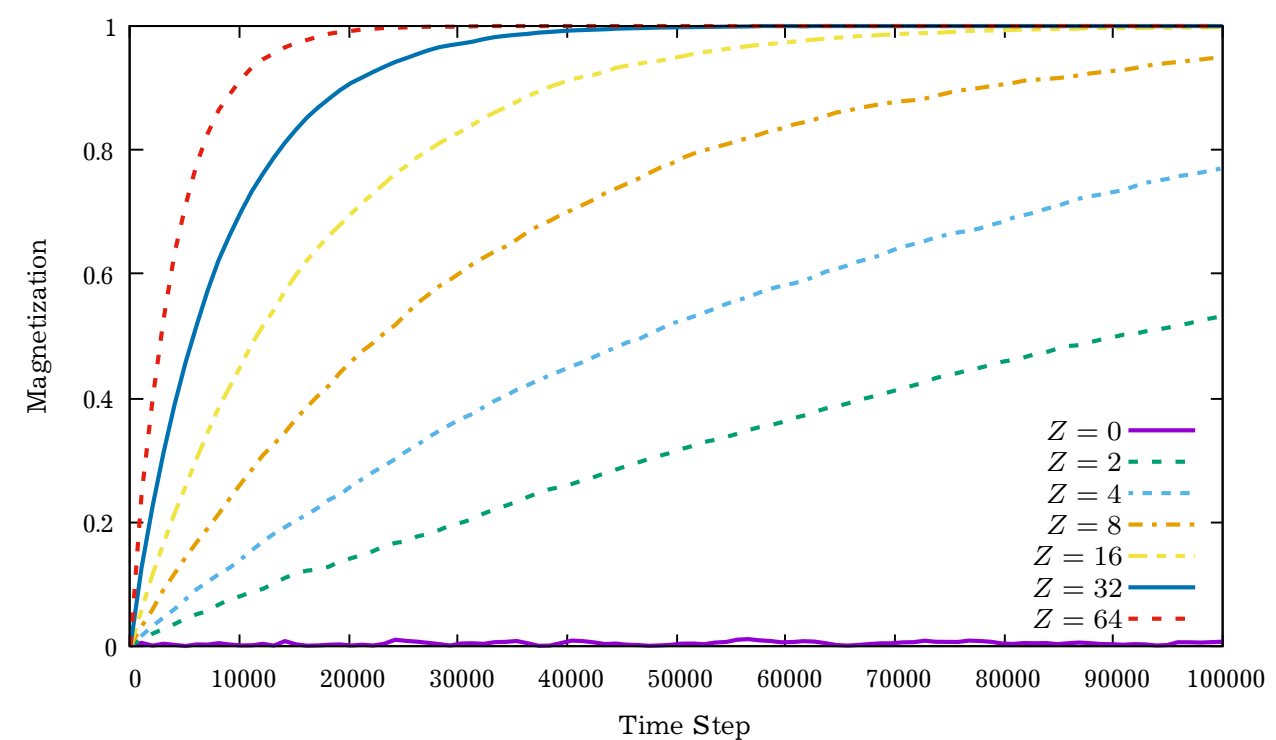

Fig. 1. The relation of zealots' quantity and system consensus achievement time in scale-free network with 1024 nodes and 8000 links (approx.). Consensus achievement time will decrease by choosing more individuals than zealots. We examine our simulation with different numbers of zealots. In the first state, there is no zealot in networks and, as it is predictable, magnetization fluctuates around zero $(Z=0)$. By increasing the zealots' quantity, the magnetization will increase. i.e. in the case $Z=8$, the network achieved the consensus (Magnetization $=1$ ) at time step $\sim 80 \mathrm{k}$. Note that all zealots' degree is 8 and all of them are on the positive side.

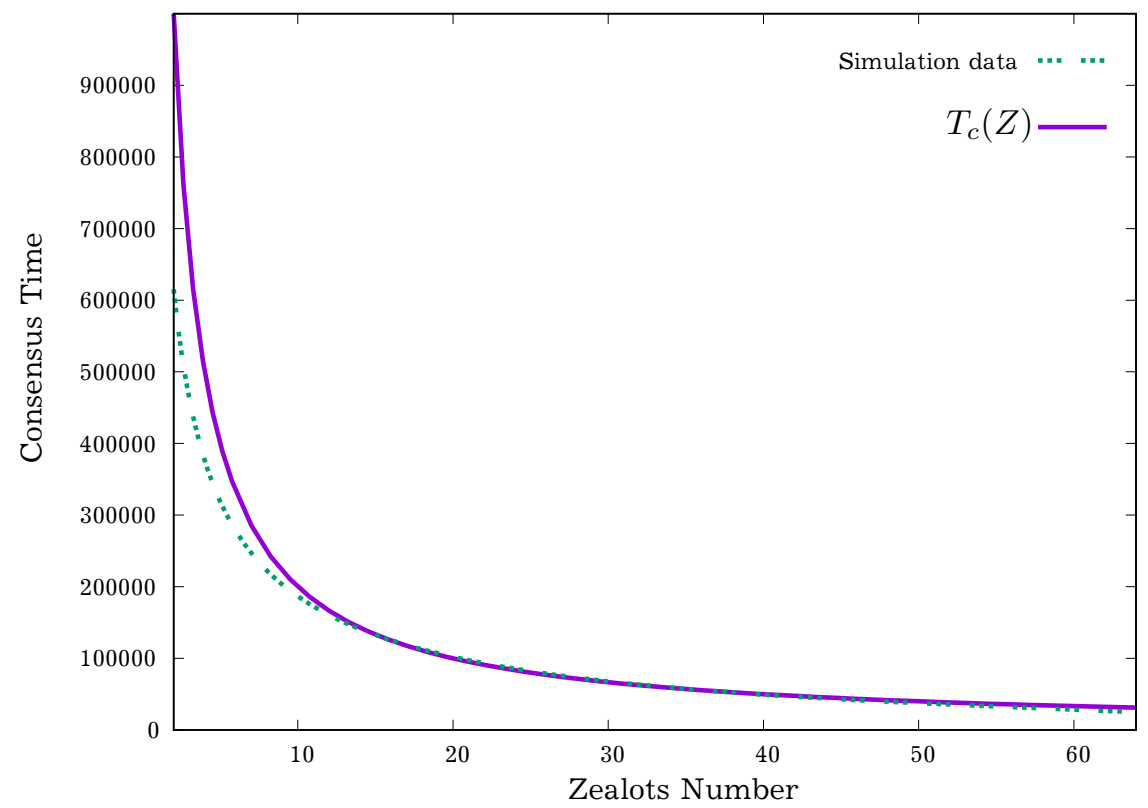

Fig. 2. Many individuals being zealots reduce consensus time. Consensus time has an exponential relation with zealots. The network is scale-free with 1024 nodes and 8000 links (approx.). We examine the modified voter model for 2 to 64 zealots, all with a degree of 8 and an opinion of 1 . This plot indicates the $T_{c}(z)$ fitting simulation data of consensus time for different zealot numbers.

Population consensus time $\left(T_{c}\right)$ has an exponential relation with zealots (Fig. 2) in scale-free networks:

$$
T_{c}(z) \sim w \times z^{-1.186}, \quad 2 \leqslant z \leqslant 64 .
$$

Here, $w$ is a constant number. Figure 2 indicates the $T_{c}(z)$ fitting simulation data of consensus time for different zealot numbers. This result shows the consensus time of the system exponentially tends 
to -1.186 with time $t$. According to Eq. (7), by increasing the number of zealots, and reducing the system consensus time, the linearly will change.

According to the network topology, and update model, individuals with positive opinion and 8 neighbours are limited. In this situation, the minimum consensus time is about $16.7 \times 10^{3}$. (At each Monte Carlo step, we choose the maximum of available zealots $\sim 100)$. It is obvious that zealots with higher degrees are more effective.

\subsection{Zealots as hubs}

In the previous section, we chose zealots with a degree of 8 . In this section, we compare zealots' effects as hubs with zealots with a degree of 8. The network is the same as last section network (1024 nodes with 8000 links (approx.)). According to this topology, in each Monte Carlo sample we can see approximately 15 hubs with a degree of more than 50, and approximately 4 hubs with a degree of more than 100. Based on Monte Carlo simulation, in each sample we have different numbers of hubs. So, we calculate the mean value of hubs in total. To compare the effects of hubs vs non-hubs, in the first case (hubs with minimum degree 50), we set 16 individuals as zealots with a degree of 8 (nearest number to 15 hubs) and in the second case (hubs with minimum degree of 100), we set 4 zealots with a degree of 8 . The result has been plotted in Fig. 3 .

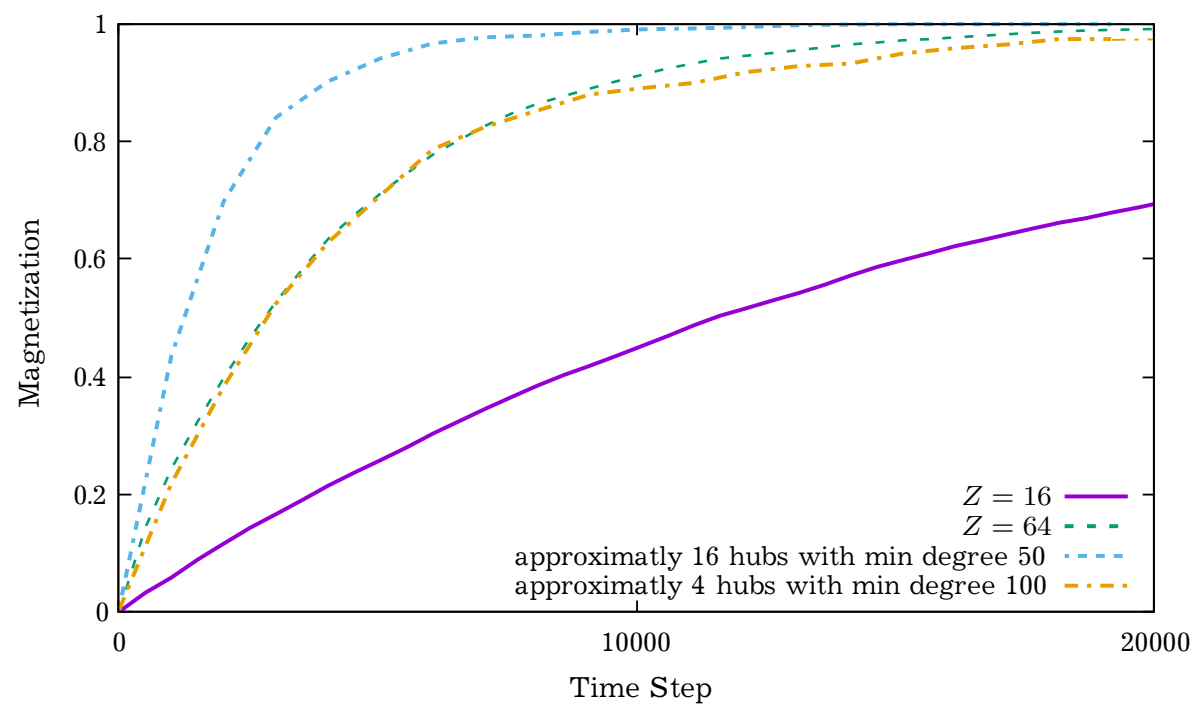

Fig. 3. As seen in this figure, hubs with less quantity have more effects on system consensus. In cases $Z=16$ and $Z=64$, there are 16 and 64 zealots with a degree of 8 , respectively. In the case with 4 hubs with the hub degree of more than 100, we have the same consensus trend with the case $Z=64$, and it is because of the same links that contaminate with zealotry.

Another result that we can observe in Fig. 3 as overlapping of system magnetization in "the case with 4 hubs as zealots with a degree of more than 100" and "the case with 64 zealots with a degree of 8". It is shown, in two mentioned cases we have the same links that they include zealotry, i.e. that total degree of all zealots in two cases are equal. For further examination of this issue, we performed more simulations. In case with 8 zealots with a degree of 8 , we have $64(=8 \times 8)$ links which includes zealotry. The equal situation to this is approximately 6 zealots with a degree of 11 (66 links that include zealotry). It is expected that system magnetization in these two cases overlaps (Fig. 4). We also plot 3 other sets with the same links, as descripted below:

1. The 8 zealots with a degree of $8 \sim 6$ zealot with a degree of 11 ;

2. The 16 zealots with a degree of $8 \sim 10$ zealots with a degree of 13 ;

3. The 32 zealots with a degree of $8 \sim 23$ zealot with a degree of 11 . 


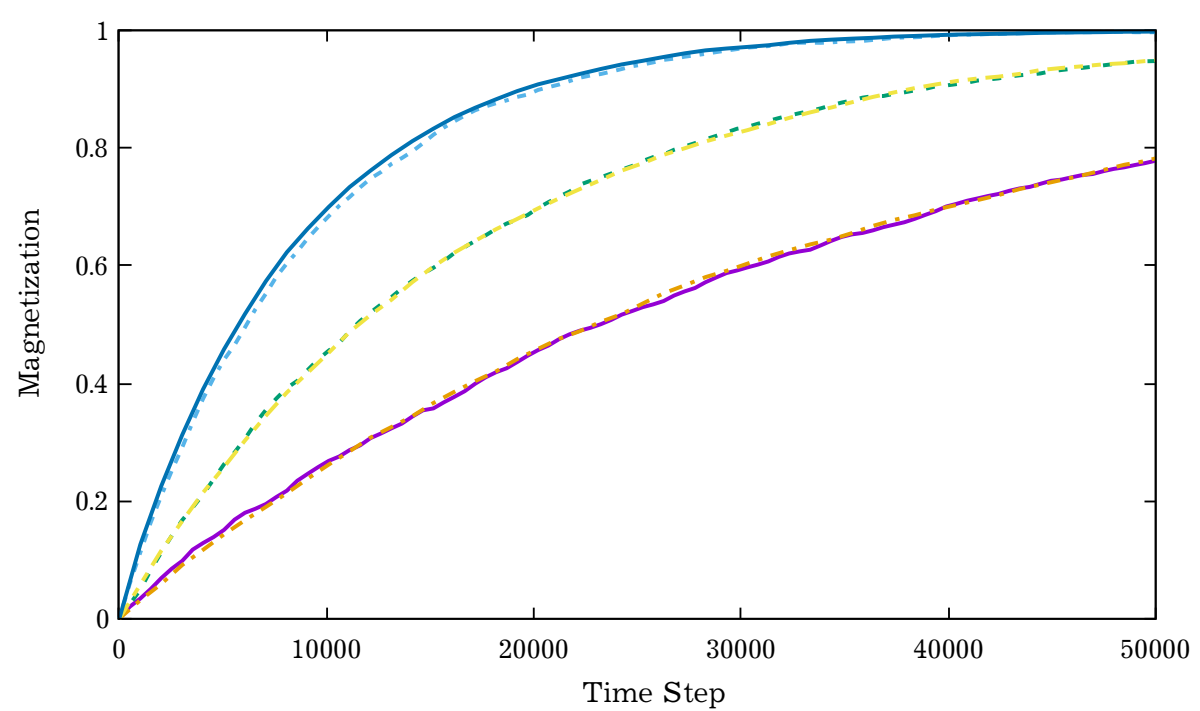

Fig. 4. Sets that cover each other with the same edge. Sets from bottom to top are sets I, II, III, respectively. The consensus trend for different numbers of zealots but with same links which includes zealotry is the same. For example, for the set II (the middle line) we have two simulations; one with 16 zealots with a degree of 8 and another with 10 zealots with a degree of 13 . In the first case we have 128 links $(16 \times 8)$ that include zealotry, and for the second case we have 130 links $(10 \times 13)$ that include zealotry that are near each other and consensus trend covers both as well.

As seen in Fig. 4, the sets containing the same edge have the same effect on system magnetization, so it is convincing that in the study of zealotry, in addition to "individuals" contamination with zealotry, we also pay attention to the "relationships" contamination with zealotry.

According to Eq. (7) for set II we have:

$$
\frac{16^{-1.186}}{8} \sim \frac{10^{-1.186}}{13}
$$

In the first part, 16 refers to the number of zealots and 8 refers to the degree of zealots. In the second part, 10 refers to zealots and 13 refers to the degree of zealots.

Further, to study the effect of zealots we set them even on negative and the positive sides. Initial population of positive and negative opinions is the same. Here, to investigate the hubs' effects, we set positive hubs as zealots (approximately 4 hubs). And hubs on the negative side are not zealots. But 32 individuals with a degree of 8 are zealots and they are in competition with only 4 positive hubs with a degree of more than 50 (see Case I in Fig. 5). It seems even 32 non-hub zealots are not enough to compete with only 4 hub zealots. By increasing zealots on the negative side to 64 , the population came to a steady-state fluctuation of around 0.3 (see Case II in Fig. 5).

Where the curve of magnetization at steady state $\left(m_{s}\right)$, has good fitness as:

$$
m_{s}=\frac{Z_{+}-Z_{-}}{Z_{+}+Z_{-}}
$$

\section{Zealots based on closeness centrality}

Centrality refers to the extent to which a vertex of a graph is centrally located in a graph [20]. In graph theory, nodes with high closeness are noteworthy. Closeness centrality is a measure of centrality in a graph, which is the sum of the length of the shortest paths between the nodes and all other nodes. In this paper, in addition to selecting hubs as zealots, we set zealots based on their closeness. To find the shortest path between nodes we use Dijkstra algorithm. Our network nodes' closeness is between 0.3 to 0.5 . We set 4 individuals as zealots on the positive side with different closeness. The initial number 


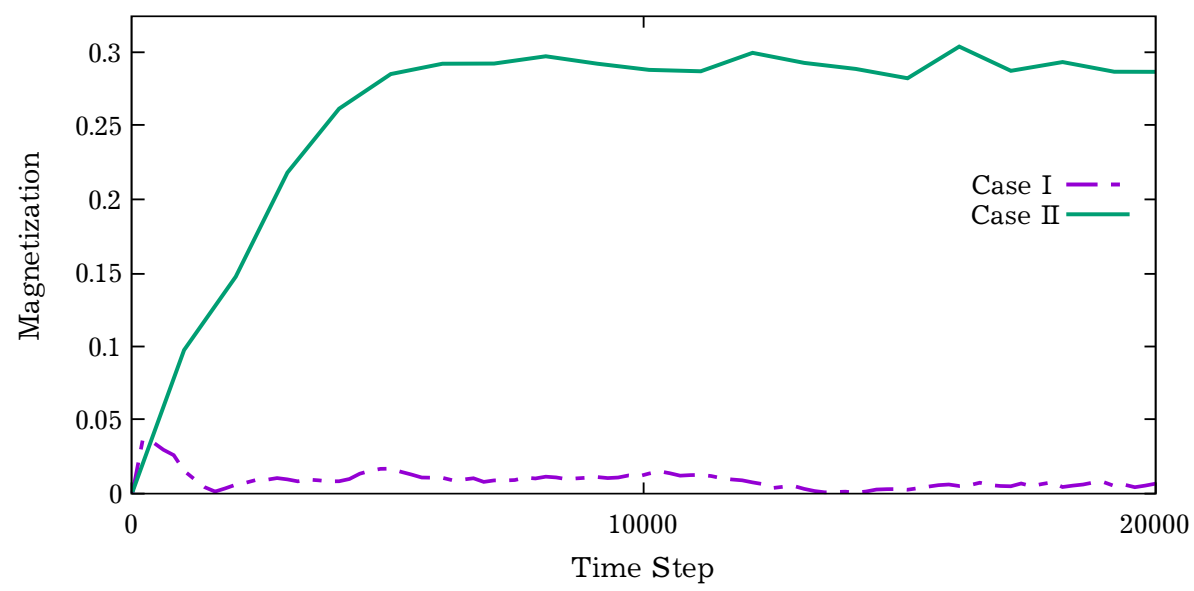

Fig. 5. The competition of hubs and non- hubs as zealots. In case II, because of the zealots on the opposite side that never change their opinions, population magnetization fluctuates around 0.3 value and network will never reach consensus. In case I we have 4 hubs with a degree of more than 50 on positive side and 32 zealots with a degree of 8 on the opposite side (negative side). Magnetization in this case fluctuates around zero, because of the equal links numbers $(\sim 250$ links) that contaminate with zealotry on each side. In case II we increase the zealotry links numbers to 512 (we set 32 zealots with degree 8) and the value of magnetization to 0.3 in favor of the negative side (The system is in steady state). But the network can never achieve the consensus state because of the zealots on the opposite side.

of positive and negative opinions is equal (Fig. 6). Our network is same as the last section network, a scale-free network with 1024 nodes.

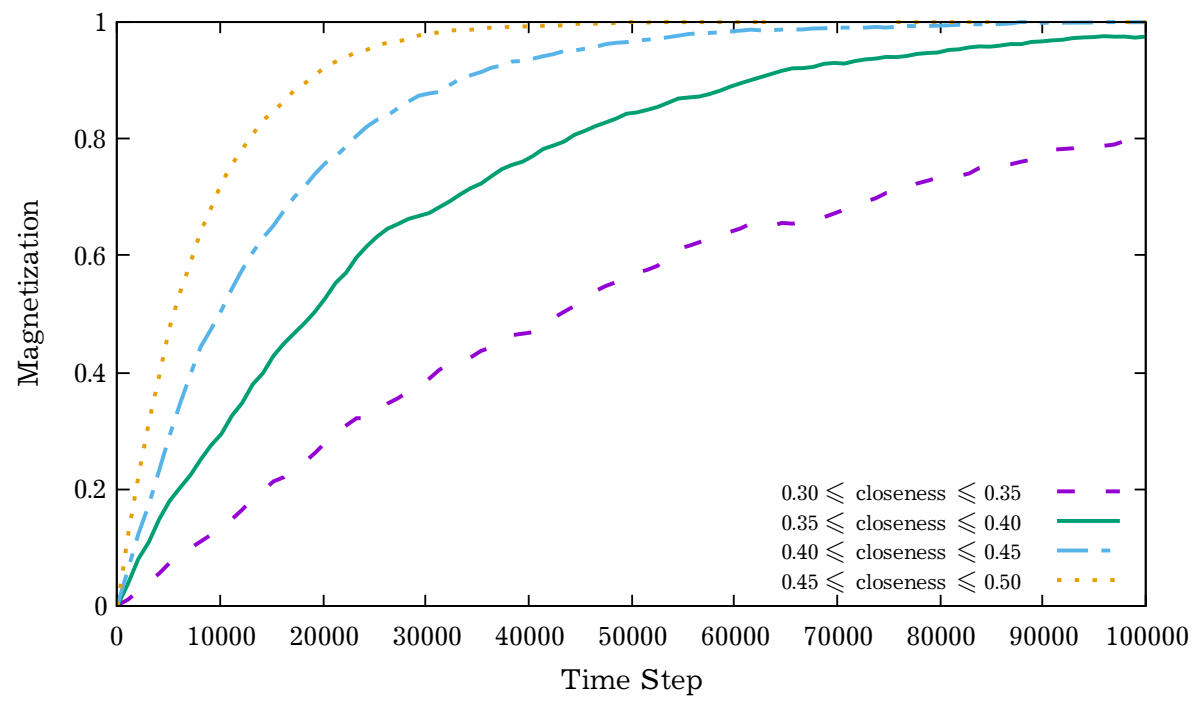

Fig. 6. The effect of zealots in consensus achievement with higher closeness. In each case we have 4 zealots with different closeness. From bottom to top the closeness of zealots increase and subsequently the time to achieve consensus decreases. Note that all zealots are on the same side.

As it was predictable, zealots with higher closeness can make the population reach to a consensus more rapidly. 


\section{Generation of simulated data set (random network)}

\subsection{Random network}

In a network (random graph), node $i$ is connected to node $j$ if there is a path from $i$ to $j$. In connected or fully-connected graphs all of the nodes $i$ and $j$ are connected directly [17]. There are two methods to generate a network of the Erdôs-Rényi random graph model:

- $G(n, E)$ : Of all possible graphs with $n$ vertices and $E$ edges, one of them is randomly selected.

- $G(n, p)$ : Generate a random graph with $n$ vertices where each possible edge has probability of containing $p$. We will use this method to generate our network of Erdôs-Rényi's model. This model was first introduced by Edgar Gilbert in 1959 [21].

\subsection{The algorithm of random network}

We started with $n=1024$ (our networks size) empty nodes. At each step, the node $i$ will be connected to the node $j$ with the probability $p=0.01(0 \leqslant p \leqslant 1)$. This step will be repeated 1024 times. By increasing probability, the network will be more connected.

In random networks, because of their properties hubs are absent. This means that most nodes have the same links, and so the random networks will have low heterogeneity. Therefore, closeness centrality of all nodes is so close to each other. This means that to get to an early consensus state, we have to choose more individuals as zealots in contrast to scale-free networks, that hubs as zealots can play an effective role in population early consensus. As seen below, the quantity of zealots has a reverse relation with system consensus time (Fig. 7). Here the random network size is 1024 and all zealots have a degree of 10 .

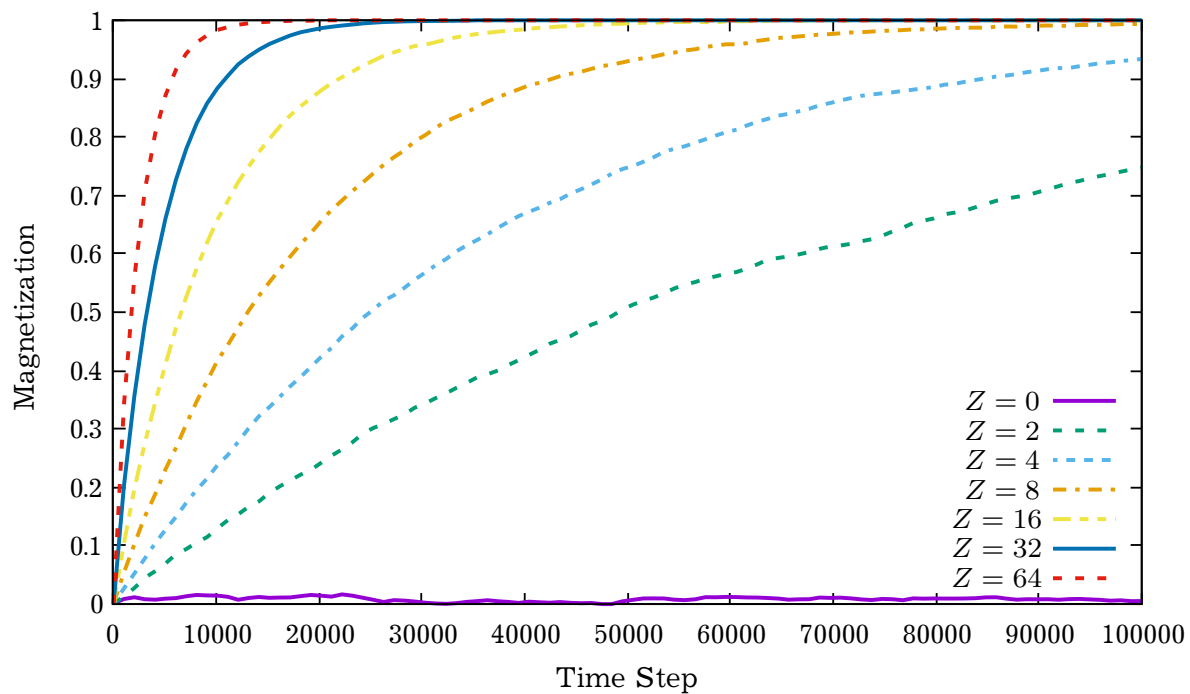

Fig. 7. The effect of zealots in consensus state achievement in random network. All of the zealots have a degree of 10 and are on the same side. The relation of zealots' quantity and system consensus achievement time in random network with 1024 nodes. Consensus achievement time will decrease by choosing more individuals as zealots. We examine our simulation with different numbers of zealots. In the first state, there is no zealot in networks and its predictable magnetization fluctuates around zero $(Z=0)$. By increasing the zealots' quantity, the magnetization will increase. i.e. in case $Z=8$ the network achieved consensus (Magnetization $=1$ ) at time step $\sim 100 \mathrm{k}$.

Same to scale-free network, in random network, zealots with a higher degree or with higher closeness can affect the opinion dynamics of the population more. And similarly, other complex networks, different numbers of zealots with the same link have the same effect on opinion dynamics. 


\section{Performance on real-world networks}

To determine the mathematical result on real networks we also simulate our modified voter model on real network [22]. We used Author collaboration network (ACN) includes 2288 nodes (present authors) and 4190 links (denote co-authorship of paper between two authors- note that in order to bring this network closer to our mathematical models, we ignored the self-loops. So total links quantity are 1144). This network degree distribution is same as scale-free network presented in Fig. 8.

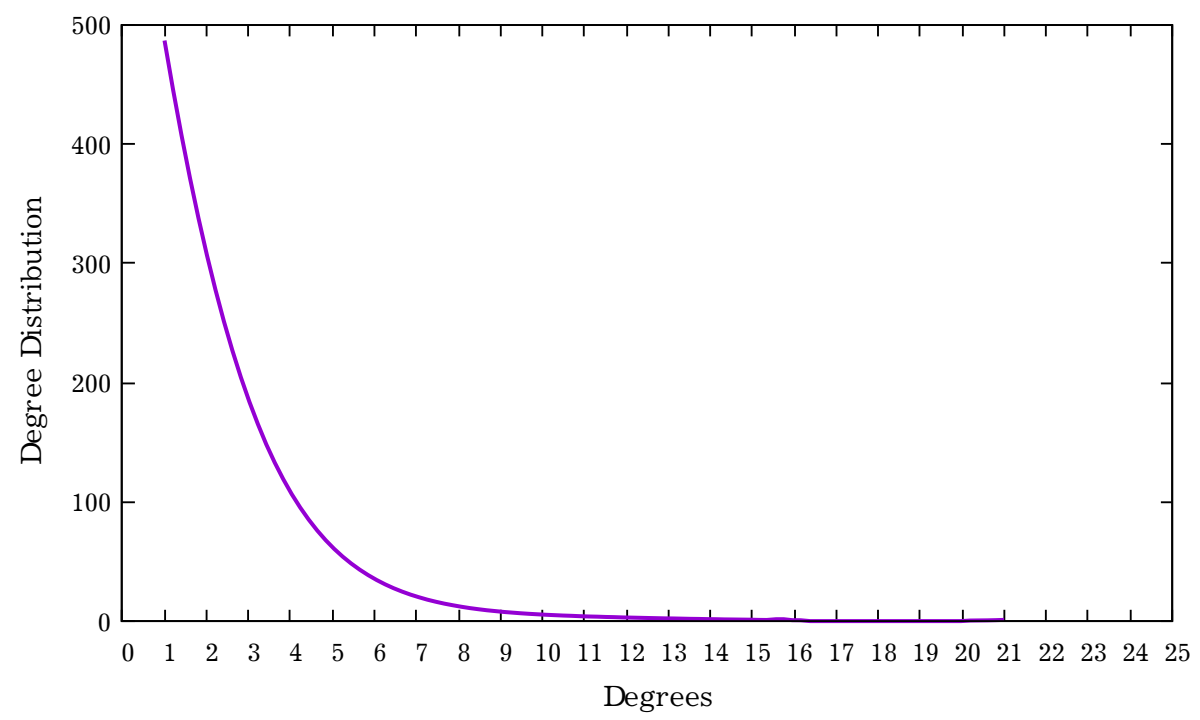

Fig. 8. Degree distribution of ACN. As it is clear from the distribution of degrees, the network is of type scale-free. It is noteworthy that in order to bring this network closer to mathematical models, we ignored the self-loops.

Network density plays an important role in population consensus. In our previous networks, for example, the density of the scale-free network is 0.015 , which greatly increases the effects of the zealots. But in the network used in this section the density is very low (About 0.0004). This low density can also be understand in Fig. 8. Many nodes have degree 1, 2 and 3 (the average node degree $\langle k\rangle$ is equal to 1$)$. This is while in the scale-free network, the average node degree $\langle k\rangle$ is equal to 8.

Firstly, we choose $0,4,16$ and 128 individuals as zealots all with the same degree of 2 . Initial population of positive and negative opinions are the same. In Fig. 9, we investigate the role of zealots in consensus achievement. As seems below, the quantity of zealots has a reverse related to the population consensus time.

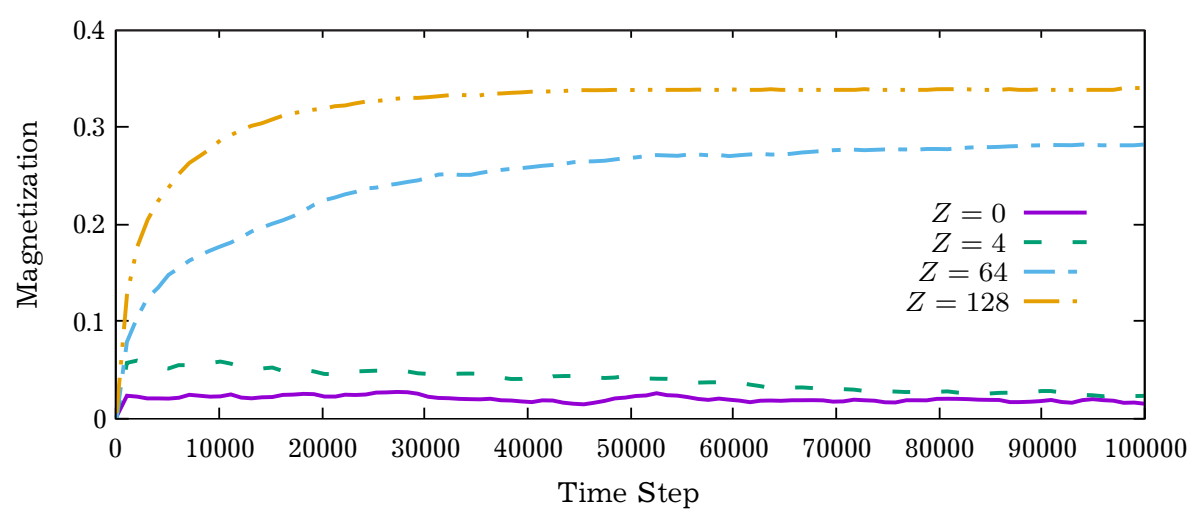

Fig. 9. The relation of zealots' quantity and network consensus achievement time in a real scale-free network with 2288 nodes and 1144 links. Population magnetization will increase by choosing more individuals as zealots.

But it seems never to reach consensus because of low density of network. 


\section{Conclusions}

In opinion dynamics models, two different spins are in competition with each other to persuade the other spins to the opposite side. Zealots, with a property that they never change their opinions, in a population, even in a small fraction, can bring the population to a consensus state. We established that this time depends on zealots and their degrees. First, we choose the zealots from nodes with a degree of 8 . In our network, the average degree is 8 . Thus, zealots were chosen from normal nodes in social networks. In this situation, to get an early consensus, the number of zealots should increase. In scale-free networks when hubs are not absent, by choosing fewer nodes that are hubs as zealots, the opinion dynamics changes become more intense. Thus, zealots with a high degree (hubs) or with high closeness centrality are more effective than zealots with an average degree. Also, when zealots are on the losers' side, it will never allow the population to get consensus, and it is because of this simple property of theirs: they never change their opinions. And finally, a population fluctuates around the value depending on the number of positive and negative zealots $\frac{Z_{+}-Z_{-}}{Z_{+}+Z_{-}}$.

We also established that the effects of 1 zealot and several zealots with the same degrees are equal. The result of Fig. 4 proves this equality. Zealots play the role of partisans in parties. Of course, it is clear that if these partisans are popular in society, their influence on the formation of ideas will be enormous, as it was seen that zealots can get the network to consensus.

In random networks with different structures, we can see the effects of zealots. The effects of zealots are the same, but here because of the absence of hubs to decrease the consensus time the only way is to increase the zealots' number.

Finally, we generated our modified voter model on the real network. Although the network density was very low, similar to the other two networks, we were able to see the zealots effect well.

[1] Krapivsky P. L. A Kinetic View of Statistical Physics. Cambridge University Press (2010).

[2] Liggett T. M. Interacting Particle Systems. Springer (1985).

[3] Clifford P., Sudbury A. A model for spatial conflict. Biometrika. 60 (3), 581-588 (1973).

[4] Mobilia M. Commitment Versus Persuasion in the Three-Party Constrained Voter Model. Journal of Statistical Physics. 151, 69-91 (2013).

[5] Gunton J. D., San Miguel M., Sahni P. Phase Transitions and Critical Phenomena. Vol. 8. London, Academic Press (1983).

[6] Suchecki K., Eguíluz V. M., San Miguel M. Conservation laws for the voter model in complex networks. Europhysics Letters. 69 (2), 228-234 (2005).

[7] Mobilia M., Petersen A., Redner S. On the role of zealotry in the voter model. Journal of Statistical Mechanics: Theory and Experiment. 8, P08029-P08029 (2007).

[8] Mobilia M. Does a Single Zealot Affect an Infinite Group of Voters? Physical Review Letters. 91 (2), 028701 (2003).

[9] Masuda N. Opinion control in complex networks. New Journal of Physics. 17 (3), 033031 (2015).

[10] Khalil N., San Miguel M., Toral R. Zealots in the mean-field noisy voter model. Phys. Rev. E. 97 (1), 012310 (2018).

[11] Barabási A.-L., Albert R. Emergence of Scaling in Random Networks. Science. 286 (5439), 509-512 (1999).

[12] Barabási A.-L. Network Science. Vol. 1. Cambridge University Press (2016).

[13] Albert R., Jeong H., Barabási A.-L. Error and attack tolerance of complex networks. Nature. 406, 378-382 (2000).

[14] Albert R., Barabási A.-L. Statistical mechanics of complex networks. Reviews of Modern Physics. 74 (1), 47-97 (2002).

[15] Bavelas A. Communication Patterns in Task-Oriented Groups. The Journal of the Acoustical Society of America. 22, 725-730 (1950).

Mathematical Modeling and Computing, Vol. 8, No. 2, pp. 203-214 (2021) 
[16] Freeman L. C. Centrality in social networks conceptual clarification. Social Networks. 1 (3), 215-239 (1978).

[17] Gündüç S., Eryiğit R. The role of persuasion power on the consensus formation. Physica A: Statistical Mechanics and its Applications. 426, 16-24 (2015).

[18] Gündüç S. The role of fanatics in consensus formation. International Journal of Modern Physics C. 26 (3), $1-18$ (2014).

[19] Suchecki K., Eguíluz V. M., Miguel M. S. Voter model dynamics in complex networks: Role of dimensionality, disorder, and degree distribution. Physical Review E. 72 (3), 036132 (2005).

[20] Sabidussi G. The centrality index of a graph. Psychometrika. 31, 581-603 (1966).

[21] Gilbert E. N. Random Graphs. Ann. Math. Statist. 30 (4), 1141-1144 (1959).

[22] Blagus B. M. The network of collaboration: Informatica and Uporabna Informatika. Uporabna Informatika (2005).

[23] Porter M., Gleeson J. Dynamical Systems on Networks. Springer (2016).

[24] Czepiel J. A. Word-of-Mouth Processes in the Diffusion of a Major Technological Innovation. Journal Of Marketing Research. 11 (2), 172-180 (1974).

[25] Beauchamp M. A. An improved index of centrality. Behavioral Science. 10, 161-165 (1965).

[26] Mobilia M., Georgiev T. Voting and catalytic processes with inhomogeneities. Physical Review E. 71 (4), $046102(2005)$.

[27] Cohn B., Marriott M. Networks and Centers in the Integration of Indian Civilization. Journal of Social Research (Ranchi). 1, 1-9 (1958).

\title{
Вплив фанатиків на динаміку думок у складних мережах
}

\author{
Моейніфар В., Гюндюк С.
}

Кафедра обчислювальної техніки Інженерного факультету Університету Анкари, Анкара, Туреччина

\begin{abstract}
У цій статті вивчається вплив фанатиків на соціальні мережі. Розглядувана соціальна мережа заснована на безмасштабних мережах із використанням методу БарабашіАльберта та випадкових мереж із використанням методу Ердос-Рені. Використовувалася попередньо вивчена модифікована модель виборця, яка включає фанатиків людей, які ніколи не змінюють своєї думки. Вибрано видатних особистостей (тобто хабів) як фанатиків. Таким чином, спочатку вибрано за фанатиків важливих людей із високим ступенем (хабів); пізніше - людей із високим ступенем близькості. А потім проаналізовано час досягнення консенсусу у випадку, коли фанатики вибираються як неважливі особистості та порівняно результати усіх випадків. Виявлено, що час для досягнення консенсусу в соціальних мережах однаковий для різної кількості фанатиків, але з однаковим ступенем зараженості фанатизмом. Наприклад, ефект одного фанатика зі ступенем 64 збігається з ефектом 8 фанатиків зі ступенем 8.
\end{abstract}

Ключові слова: модель вибория, фанатик, випадковий, без масштабу, мережі, Ердос-Рені, Барабаші-Алъберт, центр, близькість, центральність. 